\title{
A randomized double blind crossover placebo-controlled clinical trial to assess the effects of a mouthwash containing chlorine dioxide on oral malodor
}

\author{
Kayoko Shinada*, Masayuki Ueno, Chisato Konishi, Sachiko Takehara, \\ Sayaka Yokoyama and Yoko Kawaguchi
}

Address: Department of Oral Health Promotion, Graduate School, Tokyo Medical and Dental University, 1-5-45 Yushima, Bunkyo-ku, Tokyo $113-$ 8549, Japan

Email: Kayoko Shinada* - shinada.ohp@tmd.ac.jp; Masayuki Ueno - ueno.ohp@tmd.ac.jp; Chisato Konishi - mori.ohp@tmd.ac.jp; Sachiko Takehara - takehara.ohp@tmd.ac.jp; Sayaka Yokoyama - yokoyama.ohp@tmd.ac.jp; Yoko Kawaguchi - yoko.ohp@tmd.ac.jp

* Corresponding author

Published: 9 December 2008

Trials 2008, 9:71 doi:10.1186/1745-62/5-9-7|

This article is available from: http://www.trialsjournal.com/content/9///7।

(c) 2008 Shinada et al; licensee BioMed Central Ltd.

This is an Open Access article distributed under the terms of the Creative Commons Attribution License (http://creativecommons.org/licenses/by/2.0), which permits unrestricted use, distribution, and reproduction in any medium, provided the original work is properly cited.

\begin{abstract}
Background: Previous research has shown the oxidizing properties and microbiological efficacies of chlorine dioxide $\left(\mathrm{ClO}_{2}\right)$, however, its clinical efficacies on oral malodor have been evaluated only with organoleptic measurements (OM) or sulphide monitors. No clinical studies have investigated the inhibitory effects of $\mathrm{ClO}_{2}$ on volatile sulfur compounds (VSCs) using gas chromatography (GC). The aim of this study was to assess the inhibitory effects of a mouthwash containing $\mathrm{ClO}_{2}$ on morning oral malodor using OM and GC.
\end{abstract}

Methods: A randomized, double blind, crossover, placebo-controlled clinical trial was conducted among 15 healthy male volunteers, who were divided into 2 groups. In the first test phase, the group I subjects $(\mathrm{N}=8)$ were instructed to rinse with the experimental mouthwash containing $\mathrm{ClO}_{2}$, and those in group $2(\mathrm{~N}=7)$ to rinse with the placebo mouthwash without $\mathrm{ClO}_{2}$. In the second test, phase after a one week washout period, each group used the opposite mouthwash.

Oral malodor was evaluated before rinsing, right after rinsing and every 30 minutes up to 4 hours with $\mathrm{OM}$, and concentrations of hydrogen sulfide $\left(\mathrm{H}_{2} \mathrm{~S}\right)$, methyl mercaptan $\left(\mathrm{CH}_{3} \mathrm{SH}\right)$ and dimethyl sulfide $\left(\left(\mathrm{CH}_{3}\right)_{2} \mathrm{~S}\right)$, the main VSCs of human oral malodor, were evaluated with GC.

Results: The baseline oral condition in the subjects in the 2 groups did not differ significantly. The mouthwash containing $\mathrm{ClO}_{2}$ improved morning bad breath according to $\mathrm{OM}$ and reduced concentrations of $\mathrm{H}_{2} \mathrm{~S}, \mathrm{CH}_{3} \mathrm{SH}$ and $\left(\mathrm{CH}_{3}\right)_{2} \mathrm{~S}$ according to $\mathrm{GC}$ up to 4 hours after rinsing. OM scores with $\mathrm{ClO}_{2}$ were significantly lower than those without $\mathrm{ClO}_{2}$ at all examination times. Significant reductions in the concentrations of the three kinds of VSCs measured by GC were also evident at all examination times. The concentrations of the three gases with $\mathrm{ClO}_{2}$ were significantly lower than those without $\mathrm{ClO}_{2}$ at most examination times.

Conclusion: In this explorative study, $\mathrm{ClO}_{2}$ mouthwash was effective at reducing morning malodor for 4 hours when used by healthy subjects.

Trial registration: ClinicalTrials.gov NCT00655772 


\section{Background}

Oral malodor, also called halitosis or bad breath, is a general term used to describe an offensive odor emanating from the oral cavity. It is caused by several factors [1]. Although some extraoral causes (nasal inflammation, diabetes mellitus, uremia, etc.) have been suggested, clinical studies have shown that intraoral causes such as gingivitis, periodontitis and tongue coating are the main sources [24]. Volatile sulphur compounds (VSCs) (mainly hydrogen sulphide $\left(\mathrm{H}_{2} \mathrm{~S}\right)$, methyl mercaptan $\left(\mathrm{CH}_{3} \mathrm{SH}\right)$ and dimethyl sulphide $\left.\left(\left(\mathrm{CH}_{3}\right)_{2} \mathrm{~S}\right)\right)$, are the major components of malodor originating in the oral cavity. VSCs are mainly produced though putrefactive activities of bacteria residing in the oral cavity. The substrates for VSCs are sulphurcontaining amino acids (i.e. cysteine, cystine and methionine) that are found in saliva, gingival cervical fluid and tongue coating debris [5]. To target these microorganisms, and thus to treat oral malodor, different kinds of topical antimicrobial agents have been used.

Antibacterial agents such as chlorhexidine(CHX), cetylpyridinium chloride(CPC), triclosan, essential oils, zinc salts, hydrogen peroxide, sodium bicarbonate and chlorine dioxide $\left(\mathrm{ClO}_{2}\right)$ have been tested, either alone, in different combinations, or together with mechanical devices, for their efficacy to reduce oral malodor [6]. CHX being the most studied antimicrobial agent has also been tested for its efficacy in the treatment of oral malodor. Results from a case series study in halitosis patients suggested a significant effect of $0.2 \%$ or $0.12 \%$ CHX rinsing $[7,8]$. More recently, a mouthrinse formulation combining a $0.05 \%$ CHX mouthrinse with $0.05 \%$ CPC and zinc-lactate was assessed in a double-blind randomized placebo-controlled clinical trial with halitosis patients. The results after 15 days demonstrated its efficacy by significantly reducing in halitosis-related outcome variables $[9,10]$. Although CHX is considered the most effective oral antiseptic agent, the use of $\mathrm{CHX}$ for extended periods of time is related to some side-effects, such as tooth and tongue staining, bad taste and reduced taste sensation [11,12]. Notwithstanding this limitation, mouth rinses containing CHX, CPC and zinc lactate have been demonstrated clinically to be effective, monotherapy, mouth rinses to reduce oral malodor [13].

A proliferation of oral bacteria during sleep is responsible for the release of offending gases, most of which are VSCs, in morning breath even in healthy people [14]. A substantial proportion of healthy people complain of oral malodor. Healthy individuals who suffer from bad breath are likely to use mouthwashes containing several masking or antimicrobial agents. Therefore, recent papers have pointed out the relevance of comparative studies to verify the efficacy of the mouthwashes on morning bad breath in healthy subjects [15-17].
Recently a mouthwash containing chlorine dioxide $\left(\mathrm{ClO}_{2}\right)$ has become available on the Japanese market (ClO2 Fresh $^{\circledR}$, Bio-Cide International, Inc., Oklahoma, USA and Pine Medical co., Tokyo, Japan). Oral rinses containing $\mathrm{ClO}_{2}$ are now utilized in dental practices as a topical antiseptic for the oral cavity or for dentures [18-20]. Previous studies have suggested that $\mathrm{ClO}_{2}$ and chlorite anion $\left(\mathrm{ClO}_{2}^{-}\right)$directly oxidize VSCs to non-malodorous products and, through this oxidation, consume the amino acids that act as precursors to VSCs [21]. Moreover, chlorite anion is powerfully bactericidal to odorigenic microorganisms $[20,22,23]$.

In most clinical reports, oral malodor was evaluated by organoleptic measurements (OM) or the total concentration of VSCs measured by a portable sulfide monitor (Halimeter $^{\mathrm{TM}}$, Interscan co., California, USA) [18,24]. Portable sulfide monitors with a semiconductor gas sensor can detect not only VSCs but also other volatile compounds $[25,26]$. Because gas chromotography (GC) can quantitatively analyze concentrations of the three main malodor-causing substances $\left(\mathrm{H}_{2} \mathrm{~S}\right),\left(\mathrm{CH}_{3} \mathrm{SH}\right)\left(\left(\mathrm{CH}_{3}\right)_{2} \mathrm{~S}\right)$, it is considered one of the most reliable measurements for diagnosing halitosis $[27,28]$. On the other hand, OM is regarded as the gold standard for evaluating malodor clinically, although it lacks objectivity [29]. OM closely simulates any situations in which malodor is detected $[30,31]$.

Because the effective antimicrobial action of a mouthwash containing $\mathrm{ClO}_{2}$ has been verified in vitro [21], the hypothesis tested in this study is that the mouthwash will also effectively reduce oral malodor in humans when VSCs are analyzed with GC. Thus, the aim of this study was to clinically evaluate how well a mouthwash containing $\mathrm{ClO}_{2}$ reduces morning oral malodor in healthy subjects using two assessment methods, $\mathrm{OM}$ and measuring the concentrations of $\mathrm{H}_{2} \mathrm{~S}, \mathrm{CH}_{3} \mathrm{SH}$ and $\left(\mathrm{CH}_{3}\right)_{2} \mathrm{~S}$ with GC. It should be noted that this study is exploratory in design, to test the "clinical potential" of the agent $\left(\mathrm{ClO}_{2}\right)$ rather than its relative effectiveness or broad application across different population groups.

\section{Materials and methods Subjects}

Subjects were 15 healthy male volunteers aged 19-38 years (mean age $22.9 \pm 6.2$ years) who had no medical disorders, were not undergoing antibiotic or other antimicrobial therapy, and were non-smokers. The subjects received verbal and written information about the study and signed consent forms to participate. An oral examination was conducted to assess oral status of the subjects prior to the experiment. We excluded females' subjects because their menstrual cycle might affect oral malodor on the cross over design with one week washout [32]. 
The sample size was estimated using an expected mean OM score difference of 1 , a within-subject variance around the mean OM score difference of 0.5 , a significance level of $5 \%$, and a power of $80 \%$. The results indicated a required sample size of 15 subjects for a crossover design.

\section{Study design}

This clinical trial was a randomized, double blind and crossover design with a one week washout period between the crossover phases. The subjects were randomly assigned to 2 groups using a computer-generated random number. In the first test phase, the subjects in one group $(\mathrm{N}=8)$ were instructed to rinse with $10 \mathrm{ml}$ of the experimental mouthwash for 30 seconds while subjects in the other group $(\mathrm{N}=7)$ rinsed with $10 \mathrm{ml}$ of the placebo mouthwash. After the one-week washout period to exclude a carry-over effect of the experimental mouthwash, the second test phase was performed in the same way, but each subject rinsed with the opposite mouthwash. There were no significant differences in any malodor measures between the two groups at either the first or second baseline measurements before mouth rinsing. Similarly, there were no significant differences between the first and second baseline measurements after one week washout period. Hence, we think the oral condition returned to baseline during the one week washout period, and that one week washout is long enough for an explorative trial such as this.

The experimental (with $\mathrm{ClO}_{2}$ ) and the placebo mouthwashes (without $\mathrm{ClO}_{2}$ ) were prepared by Pine Medical Co. for this study. Neither the examiner nor the subject knew whether the mouthwash was experimental or placebo. The contents of each mouthwash were as follows: The experimental mouthwash $\left(\mathrm{ClO}_{2}\right.$ Fresh $\left.{ }^{\circledR}\right)$ contained $0.16 \%$ sodium chlorite $\left(\mathrm{NaClO}_{2}\right)$ with an efficacy of $0.1 \%$ chlorine dioxide $\left(\mathrm{ClO}_{2}\right)$, glycerin, mint oil, $1.13 \%$ citric acid (a pH adjusting agent) and distilled water. The placebo mouthwash contained glycerin, mint oil and distilled water; essentially the same contents as those in the experimental mouthwash except for the $\mathrm{ClO}_{2}$. Both mouthwashes were thoroughly membrane filtered and put into plastic bottles sealed with a screw-cap.

\section{Oral malodor assessment}

Measurements were conducted at around 9 o'clock in the morning to evaluate morning breath odor. Subjects were instructed to abstain from eating strong-smelling foods for at least 48 hours, from using scented cosmetics for 24 hours and from drinking alcohol for 18 hours before the assessment. In addition, they were advised not to ingest any food or drink, and to omit their usual oral hygiene practice on the morning of the assessment day [15]. Oral malodor was evaluated before rinsing (baseline), just after rinsing and every 30 minutes thereafter $(0,3,30,60,90$, $120,150,180,210,240$ minutes after rinsing) for 4 hours.

\section{Organoleptic Measurement}

The OM score was measured by two trained judges after subjects closed their mouth for 3 minutes. Judges were asked to rate malodor on a $0-5$ score, where a score of 0 represented absence of odor, 1 barely noticeable odor, 2 slight malodor, 3 moderate malodor, 4 strong malodor and 5 severe malodor [33]. If two judges gave different scores a mean score was used as the representative score for the subject. The inter-examiner reliability, using Cohen's kappa test, was 0.72-0.76.

\section{Gas chromatography analysis}

The GC analysis was carried out using a GC8A gas chromatograph (Shimadzu co., Kyoto, Japan), equipped with a flame photometric detector. After subjects closed their mouth for 3 minutes, the Teflon ${ }^{\circledR}$ tube connected to the auto-injector was inserted into the center of the oral cavity through the lips and teeth, while the lips remained closed. Following aspiration of $20 \mathrm{ml}$ of mouth air with a syringe connected to the outlet of the auto-injector, a $10 \mathrm{ml} \mathrm{sam}$ ple of air was transferred to the column and chromatograph [34]. A sulfur chemiluminescence detector that specifically responds to sulfur was used. VSCs were identified by characteristic retention times and were quantified via comparison of their peak area with that of dilutions of standards. Standard gases of $\mathrm{H}_{2} \mathrm{~S}, \mathrm{CH}_{3} \mathrm{SH}$ and $\left(\mathrm{CH}_{3}\right)_{2} \mathrm{~S}$ were prepared with a PD-1B permeater (Gastec co., Kanagawa, Japan). Before the assessment, the ambient air was used for a baseline calibration. Olfactory threshold levels: $\mathrm{H}_{2} \mathrm{~S}>1.5 \mathrm{ng} / 10 \mathrm{ml}, \mathrm{CH}_{3} \mathrm{SH}>0.5 \mathrm{ng} / 10 \mathrm{ml}$ and $\left(\mathrm{CH}_{3}\right)_{2} \mathrm{~S}$ $>0.2 \mathrm{ng} / 10 \mathrm{ml}$, were used according to Tonzetich's criteria [1].

\section{Statistical Analysis}

Statistical analysis was performed using the software program Statistical Package of Social Science (SPSS 15.0J). Means and standard deviations of the clinical indices were calculated, following which the oral examination scores between the two mouthwashes were compared with a Student's t-test. The differences of OM scores and the concentrations of the VSCs between before and after rinsing at each examination point were analyzed with paired t-tests. To detect significant differences of malodor changes between the two mouthwashes, two-factor repeated ANOVA and post-hoc paired t-tests were applied. For all the analyses, a 5\% significance level was used.

\section{Ethical approval and registration}

The Ethical Committee for Human Research at Tokyo Medical and Dental University approved this clinical study (No.238). The trial is registered with ClinicalTrials.gov protocol registration system, ID NCT00655772. 


\begin{tabular}{|c|c|c|c|c|c|c|c|c|c|c|c|c|}
\hline & Cont. $(n=15)$ & mean (SD) & $4.88(6.61)$ & $3.70(7.24)$ & $3.30(3.83)$ & $3.34(3.36)$ & 3.74 (3.89) & $4.79(4.67)$ & $6.45(8.36)$ & $4.99(4.65)$ & $4.49(4.65)$ & $6.77(5.96)$ \\
\hline \multirow[t]{2}{*}{$\mathrm{CH} 3 \mathrm{SH}(\mathrm{ng} / \mathrm{lOml})$} & 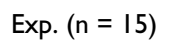 & & & & & & & & & & & \\
\hline & Cont. ( & hean & & $0.61 *(0.81)$ & 0.80 & $0.94(0.79)$ & & 1.40 & $.76)^{\prime}$ & & & $1.51)$ \\
\hline \multirow[t]{2}{*}{$\mathrm{CH} 3) 2 \mathrm{~S}(\mathrm{ng} / \mathrm{l} 0 \mathrm{ml})$} & xp. (n & ean (SD) & $.40(0.27)$ & $0.02 * *(0.06)$ & $0.05 * *(0.20)$ & $0.10^{* *}(0.16)$ & $0.09 * *(0.13)$ & $0.12^{* * *}(0.14)$ & $0.10^{* *}(0.12)$ & $0.12^{* *}(0.16)$ & $0.13^{* *}(0.12)$ & $0.10^{\text {** }}(0.12)$ \\
\hline & Cont. $(n=15)$ & mean (SD) & $0.33(0.33)$ & $0.22 *(0.21)$ & $0.28(0.26)$ & $0.29(0.25)$ & $0.34 *(0.30)$ & $0.46(0.35)$ & $0.52(0.39)$ & $0.43(0.40)$ & $0.42(0.38)$ & 0.53 ** $(0.40)$ \\
\hline
\end{tabular}

OM, organoleptic measurement; $\mathrm{H}_{2} \mathrm{~S}$, hydrogen sulfide; $\mathrm{CH}_{3} \mathrm{SH}$, methyl mercaptan; $\left(\mathrm{CH}_{3}\right)_{2} \mathrm{~S}$, dimethyl sulfide; Exp., experimental group; Cont., control group; $\mathrm{SD}$, standard deviation. *, p < 0.05; **, $\mathrm{p}<$ 0.01 conparision with the baseline (before rinsing) value. Paired t-test was used for statistical analysis. 


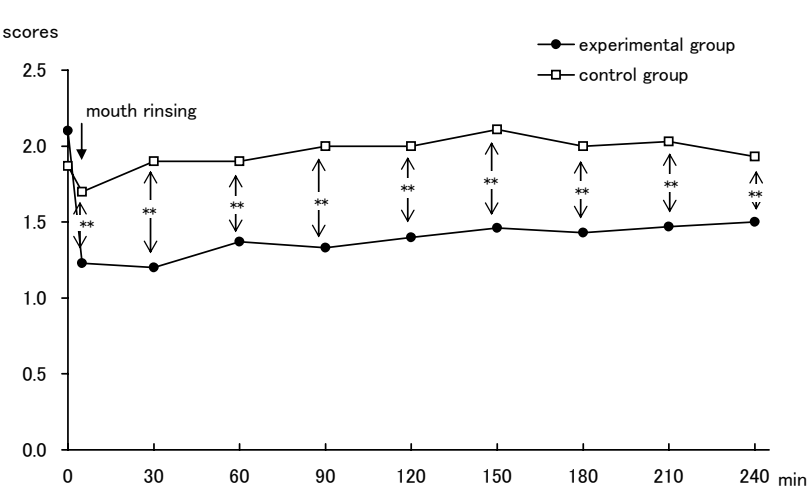

Figure I

Changes in organoleptic measurement scores. Comparison of mean $\mathrm{OM}$ values between rinsing with $\mathrm{ClO}_{2}(\mathrm{n}=$ I5) and rinsing without $\mathrm{ClO}_{2}(n=15)$ by Student's t-test. **, $p<0.01$.

\section{Results}

\section{Characteristics and oral status of subjects}

All 15 subjects completed the study. Oral statuses of the subjects were as follows (mean \pm S.D.): mean number of decayed teeth from dental caries (DT): $2.7 \pm 2.0$, missing teeth (MT): $0.5 \pm 1.4$, filled teeth (FT): $5.6 \pm 4.2$, DMFT: $8.7 \pm 5.2$, mean periodontal pocket depth: $2.4 \pm 0.5 \mathrm{~mm}$, Gingival index [35]: $1.1 \pm 0.7$, Plaque index [36]: $1.1 \pm 0.6$ and resting saliva flow rate: $0.4 \pm 0.2 \mathrm{ml} / \mathrm{min}$. There were no statistically significant differences in the oral conditions of the subjects in the 2 groups at the beginning of the study.

\section{Organoleptic measurement}

Changes of means and standard deviations for OM scores are presented in Table 1 . At baseline, the mean score in

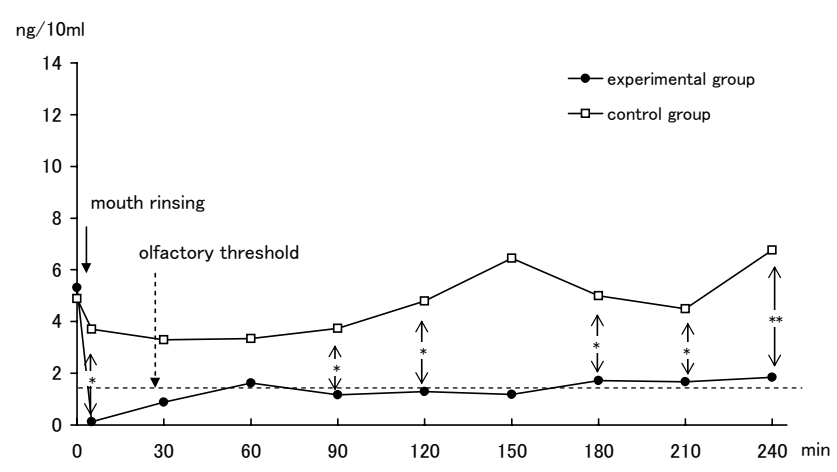

Figure 2

Changes in concentration of H2S. Comparison of mean $\mathrm{H}_{2} \mathrm{~S}$, hydrogen sulfide; Olfactory threshold levels, $\mathrm{H}_{2} \mathrm{~S}>\mathrm{I} .5$ $\mathrm{ng} / \mathrm{IO} \mathrm{ml}$ values between rinsing with $\mathrm{ClO}_{2}(\mathrm{n}=\mathrm{I5})$ and rinsing without $\mathrm{ClO}_{2}(\mathrm{n}=15)$ by Student's t-test. *, $\mathrm{p}<0.05$; **, $\mathrm{p}<0.0$ l. subjects prior to using the experimental mouthwash was 2.1 , and subjects prior to using the placebo mouthwash was 1.9. There were no statistically significant differences between the two baselines. With $\mathrm{ClO}_{2}$, the mean score fell to 1.2 just after rinsing, following which the mean score gradually rose to 1.5 , four hours later. Throughout the study the OM score was below 2, a slight malodor level. Statistically significant improvements in oral malodor compared with before rinsing were evident for up to 4 hours.

Without $\mathrm{ClO}_{2}$, on the other hand, the score dropped to 1.7 just after rinsing but it fluctuated thereafter between 1.9 to 2.1. No statistically significant improvement in oral malodor, compared with the score before rinsing, was observed. The scores with $\mathrm{ClO}_{2}$ were significantly lower than those without $\mathrm{ClO}_{2}$ at all examination times (Figure 1).

\section{Gas chromatographic assessment}

Hydrogen sulfide: $\mathrm{H}_{2} \mathrm{~S}$

The changes of mean concentrations $(\mathrm{ng} / 10 \mathrm{ml})$ of $\mathrm{H}_{2} \mathrm{~S}$ over the four-hour test period are shown in Table 1. At baseline, the mean concentration in subjects prior to using the experimental mouthwash was $5.31(\mathrm{ng} / 10 \mathrm{ml})$, and prior to using the placebo mouthwash was 4.88 . There was no statistically significant difference between the two baselines. With $\mathrm{ClO}_{2}$, the mean concentration was reduced to 0.12 just after rinsing. The mean concentration fluctuated but remained below 1.9 for up to 4 hours. These concentrations are below or close to the olfactory threshold levels for $\mathrm{H}_{2} \mathrm{~S}(1.5 \mathrm{ng} / 10 \mathrm{ml})$. Statistically significant improvements compared with before rinsing were evident at all examination times up to 4 hours. Without $\mathrm{ClO}_{2}$, however, the change of mean concentrations was trivial. The value fell to 3.70 just after rinsing, a con-

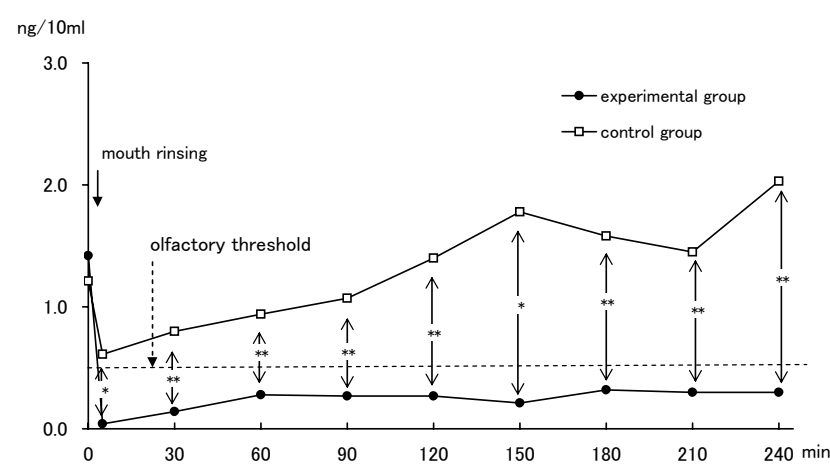

Figure 3

Changes in concentration of $\mathrm{CH} 3 \mathrm{SH}$. Comparison of mean $\mathrm{CH}_{3} \mathrm{SH}$, methyl mercaptan; Olfactory threshold levels, $\mathrm{CH}_{3} \mathrm{SH}>0.5 \mathrm{ng} / 10 \mathrm{ml}$ values between rinsing with $\mathrm{ClO}_{2}(\mathrm{n}=$ I5) and rinsing without $\mathrm{ClO}_{2}(\mathrm{n}=\mathrm{I5})$ by Student's t-test. *, $\mathrm{p}$ $<0.05$; **, $\mathrm{p}<0.01$. 


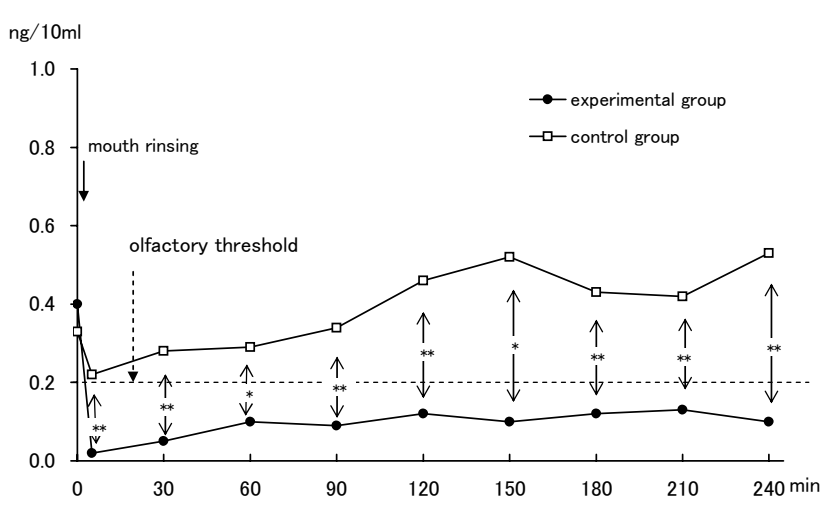

Figure 4

Changes in concentration of (CH3)2S. Comparison of mean $\left(\mathrm{CH}_{3}\right)_{2} \mathrm{~S}$, dimethyl sulfide; Olfactory threshold levels, $\left(\mathrm{CH}_{3}\right)_{2} \mathrm{~S}>0.2 \mathrm{ng} / \mathrm{lO} \mathrm{ml}$ values between rinsing with $\mathrm{ClO}_{2}(\mathrm{n}$ $=15)$ and rinsing without $\mathrm{ClO}_{2}$ by Student's t-test. $*$, $\mathrm{p}<$ $0.05 ; * *, p<0.01$.

centration still above the olfactory threshold level. The concentrations with $\mathrm{ClO}_{2}$ were significantly lower than those without $\mathrm{ClO}_{2}$ at most examination times (Figure 2).

\section{Methyl mercaptan: $\mathrm{CH}_{3} \mathrm{SH}$}

The changes of mean concentrations $(\mathrm{ng} / 10 \mathrm{ml})$ of $\mathrm{CH}_{3} \mathrm{SH}$ over the four-hour test period are shown in Table 1. At baseline, the mean concentration in subjects prior to using the experimental mouthwash was $1.42(\mathrm{ng} / 10 \mathrm{ml})$, and prior to using the placebo mouthwash was 1.21. There was no statistically significant difference between the two baselines. Immediately after rinsing with $\mathrm{ClO}_{2}$, the mean concentration declined to 0.04. Concentrations at all examining times after rinsing were much lower than the olfactory threshold level for $\mathrm{CH}_{3} \mathrm{SH}(0.5 \mathrm{ng} / 10 \mathrm{ml})$. Statistically significant improvements compared with before rinsing were evident at all examination times up to 4 hours. Without $\mathrm{ClO}_{2}$ the mean concentration fell to 0.61 (ng/10 ml), however, all measured concentrations were above the olfactory threshold levels for $\mathrm{CH}_{3} \mathrm{SH}$. The concentrations with $\mathrm{ClO}_{2}$ were significantly lower than those without $\mathrm{ClO}_{2}$ at most examination times (Figure 3).

\section{Dimethyl sulfide: $\left(\mathrm{CH}_{3}\right)_{2} \mathrm{~S}$}

The changes of mean concentrations $(\mathrm{ng} / 10 \mathrm{ml})$ for $\left(\mathrm{CH}_{3}\right)_{2} \mathrm{~S}$ over the four-hour test period are shown in Table 1. At baseline, the mean concentration in subjects prior to using the experimental mouthwash was $0.40(\mathrm{ng} / 10 \mathrm{ml})$, and prior to using the placebo mouthwash was 0.33 . There was no statistically significant difference between the two baselines. Just after rinsing with $\mathrm{ClO}_{2}$, the mean concentration decreased to 0.02, and concentrations remained below the olfactory threshold for $\left(\mathrm{CH}_{3}\right)_{2} \mathrm{~S}(0.2$ $\mathrm{ng} / 10 \mathrm{ml})$. Statistically significant improvements com- pared with before rinsing were evident at all examination times up to 4 hours. Without $\mathrm{ClO}_{2}$, the mean concentration dropped slightly to 0.22 . The concentration rose gradually thereafter, and all examined concentrations were above the olfactory threshold level. Concentrations with $\mathrm{ClO}_{2}$ were significantly lower than those without $\mathrm{ClO}_{2}$ at most examination times (Figure 4).

\section{Discussion}

As noted previously, this study design has certain limitations with respect to both generalization from the findings and relative effectiveness in comparison with other agents and the use of a positive control. In this explorative trial, we compared two mouthwashes; one with $\mathrm{ClO}_{2}$ and one without $\mathrm{ClO}_{2}$, to investigate the malodor reducing effects of $\mathrm{ClO}_{2}$. The results of this study demonstrate that rinsing with a mouthwash containing $\mathrm{ClO}_{2}$ significantly improves malodor assessed by $\mathrm{OM} . \mathrm{ClO}_{2}$ mouthwash and also effectively reduces $\mathrm{H}_{2} \mathrm{~S}, \mathrm{CH}_{3} \mathrm{SH}$ and $\left(\mathrm{CH}_{3}\right)_{2} \mathrm{~S}$ concentrations in mouth air. Such malodor reducing effects were evident up to 4 hours after rinsing.

Previous studies have suggested that $\mathrm{ClO}_{2}$ and $\mathrm{ClO}_{2}^{-}$have the ability to directly oxidize VSCs to non-malodorous products and, through this oxidation, consume amino acids such as L-cysteine and L-methionine that act as precursors to VSCs $[18,20,23]$. Moreover, chlorite anion is powerfully bactericidal to odorigenic microorganisms $[18,20,21]$. This mouthwash's effect is partially explained by the reduction of the bacterial load in the saliva and on the teeth. The clinical mechanism of oxidization of VSCs and the antibacterial action of $\mathrm{ClO}_{2}$ should be confirmed in future studies.

Frascella et al. tested the effectiveness of a $\mathrm{ClO}_{2}$-containing mouthwash at different time points for a total of 96 hours after rinsing [37]. The results showed a significant improvement in OM scores and VSCs levels measured by a portable sulfide monitor when the tested mouthwash was compared to a water control at 2 hours after rinsing. The mean VSCs concentration in the test group reached its minimum level at 8 hours after rinsing, but these clinical efficacies on oral malodor were evaluated only with OM or sulphide monitors.

There have been no clinical studies that used GC to investigate inhibitory effects of $\mathrm{ClO}_{2}$ on concentrations of $\mathrm{H}_{2} \mathrm{~S}$, $\mathrm{CH}_{3} \mathrm{SH}$ and $\left(\mathrm{CH}_{3}\right)_{2} \mathrm{~S}$, the main VSCs of human oral malodor. We found that rinsing with $\mathrm{ClO}_{2}$ drastically reduced the concentrations of all three, but especially $\mathrm{CH}_{3} \mathrm{SH}$, far below the olfactory threshold level.

Periodontal disease causes high concentrations of VSCs in mouth air. The concentrations of $\mathrm{CH}_{3} \mathrm{SH}$ are significantly higher in patients with periodontal disease than those in 
orally healthy individuals [5]. Although the current study was conducted with orally healthy subjects, the results suggest that a mouthwash containing $\mathrm{ClO}_{2}$ might lower oral malodor in patients with periodontal disease. However we need to examine the long-term effect as well as the effect on periodontal disease and microbiological consideration of the mouthwash in a future research.

Recently, many over-the-counter mouthwashes have been used in the treatment of oral malodor. Some of these products merely mask malodor. The optimal mouthwash to treat oral malodor would be an antiseptic agent with proven long-lasting efficacy for reduction of OM and VSCs concentrations, with few side effects.

Chlorhexidine-containing mouthwashes inhibit formation of VSCs and are effective oral antiseptics with antiplaque and antigingivitis effects [38]. Although CHX is considered the most effective oral antiseptic agent, rinsing with $0.2 \%$ alcohol-free CHX for 1 week caused more irritation to oral mucosa, greater burning sensation, and increased altered taste perception compared to the placebo rinse [11]. Listerine ${ }^{\circledast}$ (Johnson and Johnson, New Jersey, USA), a mouthwash containing essential oils, has clear antiplaque and antigingivitis activity [39]. However, its high alcohol concentration reduces taste sensation and can cause oral pain [40]. Zinc ions inhibit oral malodor but tastes bad [41]. Triclosan and cetylpyridium chloride (CPC) are antimicrobial agents widely used as antiseptic agents [42]. However, their clinical reduction VSCs is questionable [6].

$\mathrm{ClO}_{2}$ is used widely in various fields for its safe and high antibacterial action $[18,19,23]$. Sodium chlorite $\left(\mathrm{NaClO}_{2}\right)$, equivalent to $\mathrm{ClO}_{2}$, the traditional ingredient in almost all oxygen supplementation today, is a nontoxic substance approved by the U.S. Food and Drug Administration (FDA) as an antimicrobial agent. We found $\mathrm{ClO}_{2}$ not only to be effective at reducing oral malodor, but also none of the volunteers complained about the $\left.\begin{array}{llllll}\text { mouthwash with } & 0.1 \% & \mathrm{ClO}_{2} & (0.16 \% & \mathrm{NaClO}_{2}\end{array}\right)$.

The FDA has established a sodium chlorite level of $0.5 \%$ $(5,000 \mathrm{ppm})$ as the maximum allowable concentration for human consumption in food products [43], which is above the level in the experimental mouthwash. Therefore, this mouthwash may have an advantage over other products for oral malodor because of its efficacy and safety.

Most former studies used healthy subjects with no complaints about malodor, lacked an adequate control and evaluated only a short-term effect of up to a few hours. Our study also investigated only short-term effects of the mouthwash and the research design is more like a study model than a clinical trial. Because we only followed our subjects for up to 4 hours our results must be applied to chronic halitosis with caution. It is not known whether the same results would be obtained from halitosis patients. Future research is needed to examine long-term effects, as well as effects on periodontal disease and plaque accumulation in a well-defined sample of halitosis patients. It is also recognized that comparative efficacy studies need to be performed against the known effective mouthrinses containing CHX and that both broader population samples, including females and halitosis patients, should be used in future research. Nonetheless, in this explorative study, the OM score was improved and VSCs concentrations were significantly reduced using the $\mathrm{ClO}_{2}$ as an agent. Therefore, the mouthwash clearly demonstrated an anti-malodor effect on morning breath potential without any measurable side effects in healthy subjects.

\section{Conclusion}

The results showed that a mouthwash containing $\mathrm{ClO}_{2}$ improved morning bad breath measured with the OM and reduced the concentrations of $\mathrm{H}_{2} \mathrm{~S}, \mathrm{CH}_{3} \mathrm{SH}$ and $\left(\mathrm{CH}_{3}\right)_{2} \mathrm{~S}$ measured by gas chromatography for up to 4 hours after mouth rinsing by healthy subjects. However, future studies are needed to examine long-term effects of the mouthwash in halitosis patients. $\mathrm{ClO}_{2}$ may have the potential to be included in the range of anti-oral malodor products used to manage this condition.

\section{Competing interests}

The authors declare that they have no competing interests.

\section{Authors' contributions}

KS has made substantial contribution to the study conception and design and obtained the ethics approval. KS, MU, CK, ST and SY implemented this study and participated in the acquisition, analysis and interpretation of data. KS, $\mathrm{MU}$ and YK have been intimately involved in drafting and editing the manuscript. All authors read and approved the final manuscript.

\section{Acknowledgements}

This clinical trial was supported by research funds from Department of Oral Health Promotion, Graduate School, Tokyo Medical and Dental University. Pine Medical Company provided the mouthwashes and some of the experimental reagents and supported part of the research funding.

\section{References}

I. Tonzetich J: Production and origin of oral malodor: a review of mechanisms and methods of analysis. J Periodontol 1977, 48: 13-20.

2. Miyazaki H, Sakao S, Katoh Y, Takehara T: Correlation between volatile sulphur compounds and certain oral health measurements in the general population. J Periodontol 1995, 66:679-684

3. Tangerman A: Halitosis in medicine: a review. Int Dent J 2002, 52(Suppl 3):20I-206.

4. Murata T, Yamaga T, lida T, Miyazaki H, Yaegaki K: Classification and examination of halitosis. Int Dent J 2002, 52(Suppl $3): 18 \mid-186$ 
5. Yaegaki K, Sanada K: Volatile sulfur compounds in mouth air from clinically healthy subjects and patients with periodontal disease. J Periodontal Res 1992, 27:233-238.

6. Roldán S, Herrera D, Sanz M: Biofilms and the tongue: therapeutical approaches for the control of halitosis. Clin Oral Invest 2003, 7:189-197.

7. Bosy A, Kulkarni GV, Rosenberg M, McCulloch G: Relationship of oral malodor to periodontitis: evidence of independence in discrete subpopulations. J Periodontol 1994, 65:37-46.

8. De Boever EH, Loesche WJ: Assessing the contribution of anaerobic microflora of the tongue to oral malodor. J Am Dent Assoc 1995, I 26: I 384-1393.

9. Roldán S, Winkel EG, Herrera D, Sanz M, Van Winkelhoff AJ: The effects of a new mouthrinse containing chlorhexidine, cetylpyridium chloride and zinc lactate on the microflora of oral halitosis patients: a dual-centre, double-blind placebocontrolled study. J Clin Periodontol 2003, 30:427-434.

10. Winkel EG, Roldán S, Van Winkelhoff AJ, Herrera D, Sanz M: The clinical effects of a new mouthrinse containing chlorhexidine, cetylpyridinium chloride and zinc-lactate on oral halitosis. A dual-center, double-blind placebo-controlled study. J Clin Periodontol 2003, 30:300-306.

II. Gürgan CA, Zaim E, Bakirsoy I, Soykan E: Short-term side effects of $0.2 \%$ alcohol-free chlorhexidine mouthrinse used as an adjunct to non-surgical periodontal treatment: a doubleblind clinical study. J Periodontol 2006, 77:370-384.

12. Lorenz K, Bruhn G, Heumann C, Netuschil L, Brecx M, Hoffmann T: Effect of two new chlorhexidine mouthrinses on the development of dental plaque, gingivitis, and discolouration. A randomized, investigator-blind, placebo-controlled, 3-week experimental gingivitis study. J Clin Periodontol 2006, 33:56 I-567.

13. Roldán S, Herrera D, O'Connor A, González I, Sanz M: A Combined therapeutic approach to manage oral halitosis: a 3-month prospective case series. J Periodontol 2005, 76:1025-1033.

14. Suarez FL, Furne JK, Springfield J, Levitt MD: Morning breath odor: influence of treatments on sulfur gases. J Dent Res 2000 , 79: $1773-1777$

15. van Steenberghe D, Avontroodt P, Peeters W, Coucke W, Lijnen A, Quirynen M: Effect of different mouthrinses on morning breath. J Periodontol 200I, 72:II83-1I9I.

16. Carvalho MD, Tabchoury CM, Cury JA, Toledo S, Nogueira-Filho GR: Impact of mouthrinses on morning bad breath in healthy subjects. J Clin Periodontol 2004, 3 I:85-90.

17. Faveri M, Hayacibara MF, Pupio GC, Cury JA, Tsuzuki CO, Hayacibara RM: A cross-over study on the effect of various therapeutic approaches to morning breath odour. J Clin Periodontol 2006, 33:555-560.

18. Silwood CJL, Grootveld MC, Lynch E: A multifactorial investigation of the ability of oral health care products (OHCPs) to alleviate oral malodour. J Clin Periodontol 200I, 28:634-64I

19. Gornitsky M, Paradis I, Randaverde G, Malo AM, Velly AM: A clinical and microbiological evaluation of denture cleansers for geriatric patients in long-term care institutions. J Can Dent Assoc 2002, 68:39-45.

20. Mohammad AR, Giannini PJ, Preshaw PM, Alliger H: Clinical and microbiological efficacy of chlorine dioxide in the management of chronic atrophic candidiasis: an open study. Int Dent J 2004, 54:154-158.

21. Lynch E, Sheerin A, Claxson AWD, Atherton MD, Rhodes CJ, Silwood CJL, Naughton DP, Grootveld M: Multicomponent spectroscopic investigations of salivary antioxidant consumption by an oral rinse preparation containing the stable free radical species chlorine dioxide $\left(\mathrm{ClO}_{2}\right)$. Free Rad Res 1997, 26:209-234.

22. Yates R, Moran J, Addy M, Mullan PJ, Wade WG, Newcombe R: The comparative effect of acidified sodium chlorite and chlorhexidine mouthrinses on plaque regrowth and salivary bacterial counts. I Clin Periodontol 1997, 24:603-609.

23. Grootveld M, Silwood C, Gill D, Lynch E: Evidence for the microbicidal activity of a chlorine dioxide-containing oral rinse formulation in vivo. I Clin Dent 200I, I 2:67-70.

24. Frascella J, Gilbert R, Fernandez P: Odor reduction potential of a chlorine dioxide mouthrinse. I Clin Dent 1998, 9:39-42.

25. Rosenberg M, Kulkarni GV, Bosy A, McCulloch CA: Reproducibility and sensitivity of oral malodor measurements with a portable sulphide monitor. J Dent Res 1991, 70:1436- | 440.
26. Furne J, Majerus G, Lenton P, Springfield J, Levitt D, Levitt M: Comparison of volatile sulfur compound concentrations measured with a sulfide detector vs. gas chrotomatography. J Dent Res 2002, 8 I: | 140-I 43.

27. Tonzetich J: Direct gas chromatographic analysis of sulphur compounds in mouth air in man. Arch Oral Biol 1971, 16:587-597.

28. Yaegaki K, Coil JM: Examination, classification, and treatment of halitosis; clinical perspectives. J Can Dent Assoc 2000, 66:257-261.

29. Broek AMWT van den, Feenstra $L$, de Baat $C$ : $\mathbf{A}$ review of the current literature on aetiology and measurement methods of halitosis. J Dent 2007, 35:627-635.

30. Greenman J, Duffield J, Spencer P, Rosenberg M, Corry D, Saad S, Lenton P, Majerus G, Nachnani S, El-Maaytah M: Study on the organoleptic intensity scale for measuring oral malodor. J Dent Res 2004, 83:8I-85.

3I. Liu XN, Shinada K, Zhang BX, Yaegaki K, Kawaguchi T: Oral malodor-related parameters in the Chinese general population. $J$ Clin Periodontol 2006, 33:3I-36.

32. Tonzetich J: Oral malodour: an indicator of health status and oral cleanliness. Int Dent J 1978, 28:309-319.

33. Rosenberg M, McCulloch CA: Measurement of oral malodor: current methods and future prospects. J Periodontol 1992, 63:776-782.

34. Sopapornamorn P, Ueno M, Vachirarojpisan T, Shinada K, Kawaguchi $Y$ : Association between oral malodor and measurements obtained using a new sulfide monitor. I Dent 2006, 34:770-774

35. Löe $\mathrm{H}$, Silness J: Periodontal disease in pregnancy. I. Prevalence and severity. Acta Odontol Scand 1963, 21:533-55।.

36. Silness J, Löe H: Periodontal disease in pregnancy. II. Correlation between oral hygiene and periodontal condition. Acta Odontol Scand 1964, 22: I II-I35

37. Frascella J, Gilbert RD, Fernandez P. Hendler J: Efficacy of a chlorine dioxide-containing mouthrinse in oral malodor. Compend Contin Educ Dent 2000, 2 I:24I-248.

38. Roldán S, Herrera D, Santa-Cruz I, O'Connor A, Gonzalez I, Sanz M: Comparative effects of different chlorhexidine mouth-rinse formulations on volatile sulphur compounds and salivary bacterial counts. / Clin Periodontol 2004, 3 I: I I 28-I I 34.

39. Charles CH, Mostler KM, Bartels LL, Mankodi SM: Comparative antiplaque and antigingivitis effectiveness of a chlorhexidine and an essential oil mouthrinse: 6-month clinical trial. J Clin Periodontol 2004, 3 I:878-884.

40. Bolanowski SJ, Gescheider GA, Suttin SVW: Relationship between oral pain and ethanol concentration in mouthrinses. J Periodont Res 1995, 30:192-197.

4I. Young A, Jonski G, Rölla G: Inhibition of orally produced volatile sulfur compounds by zinc, chlorhexidine or cetylpyridium chloride - effect of concentration. Eur J Oral Sci 2003, I I I:400-404.

42. Nogueira-Filho GR, Duarte PM, Toledo S, Tabchoury CP, Cury JA: Effect of triclosan dentifrices on mouth volatile sulphur compounds and dental plaque trypsin-like activity during experimental gingivitis development. J Clin Periodontol 2002, 29:1059-1064.

43. U.S. Food and Drug Administration (FDA) Environmental Decision Memo for Food Contact Notification No. 000450 [http://www.cfsan.fda.gov/\%20 rdb/fnsi0450.html] 